\title{
Educação interprofissional na reorientação da formação e do modelo de atenção à saúde: desafios para a saúde coletiva
}

\author{
Claudia Mara Pedrosa, Denise de Lima Costa Furlanetto
}

\begin{abstract}
Resumo
A interprofissionalidade está intrínseca na proposta de criação dos curso de graduação em saúde coletiva por trazer em sua base a proposta de superação da estrutura pedagógica tradicional e disciplinar, priorizando conhecimentos e práticas que contemplem a troca de saberes e responsabilidades mútuas para formar sanitaristas comprometidos com o Sistema Único de Saúde e com as complexas necessidades de saúde. O presente trabalho tem como proposta dialogar sobre os desafios da construção curricular do curso de saúde coletiva contemplando a interprofissionalidade. Norteadas pela novas diretrizes curriculares da saúde coletiva e pela revisão do projeto político pedagógico do curso de saúde coletiva da Faculdade de Ciências da Saúde, as autoras analisaram os documentos produzidos pelos docentes nos encontros pedagógicos do Núcleo Docente Estruturante (NDE) e avaliações dos discentes dos estágios curriculares. Foram construídas as seguintes categorias analíticas: a) identificação das necessidade da reforma do ensino em saúde coletiva na perspectiva da interprofissionalidade; b) o uso de novas metodologias pedagógicas na construção da integralização das disciplinas; c) perfil do egresso sanitarista para a atuação interprofissional. Conclui-se que apesar de os documentos analisados do NDE apresentarem objetivos e fluxos bem definidos e de complexidade crescente para construção de saberes e práticas que garantam os conhecimentos necessários para a transformação das práticas em saúde, a articulação das ações ainda não sao efetivadas no âmbito do ensino. A superação dos territórios de saberes na formação aparece como dificuldade na prática dos docentes e nos cenários de formação para a integralização da interprofissionalidade no curso. Espera-se que a enunciação das lacunas e desafios na reforma curricular da Saúde Coletiva da FS amplie os recursos pedagógicos que instrumentalizarão atores envolvidos na formação - docentes, preceptores e discentes para a construção da interprofissionalidade, considerando a equidade e a superação do modelo curricular fragmentado como elementos norteadores do processo.
\end{abstract}

Descritores: Relações Interprofissionais, Saúde Pública, Políticas Públicas de Saúde, Trabalho em Saúde Educação 